\title{
Behavioural guidance of child dental patients*
}

\author{
William E. Brown, D.D.S., M.S. $\dagger$
}

Fear of dental treatment is still one of the major blocks to optimal dental health. Too often the child visits the dentist for the first time because of an emergent problem, and the distress associated with the treatment either sours him on dental care for life or requires much effort and patience to alter $h$ is attitudes. An early first visit, between the ages of $2 \frac{1}{2}$ and 3 years, before serious troubles develop and an understanding dentist who promptly establishes good relations with the child will do much to create favourable attitudes toward dental care that will last a lifetime.

\section{Behavioural patterns}

\section{Normal children}

Most children who are physically and mentally normal and emotionally stable make excellent dental patients. A simple, pleasant first appointment often is all that is required. A prophylaxis and a complete oral examina. tion give the dentist the opportunity to establish rapport with the child and his parent. Telling the child what is to be done, showing him, and then doing it make for a sound approach. The dogmatic practice of

* Presented at the 18th Australian Dental Congress, Melbourne, February-March, 1967.

† Professor of Dentlstry and Associate Director, W. K. Kellogg Foundation Institute: Graduate and Postgraduate Dentistry, The University of Michigan. keeping the parent out of the operatory, especially during the initial visit, may not be rational for the normal child. Being present during this appointment gives the parent an opportunity to see the dentist in action and increases trust. Further, it gives the dentist time to demonstrate first hand the child's needs and to communicate dental health educational material to the child and parent together.

Operative dentistry can be performed for the normal child without significant fear or distress. The routine use of local anæsthetics administered without fanfare assures the child's comfort. The routine application of the rubber dam not only provides a clear, dry operating field and guards against wandering tongues and cheeks but it tends to promote relative immobility and greater relaxation. Good organization of equipment and instrumentation to create efficiency and a skilled chairside assistant make for shorter appointments and a happier patient.

\section{Over concerned children}

Some normal children are unduly concerned about dental treatment. This concern may be due to unpleasant past experiences, either medical or dental, parental attitudes toward their children, or a playmate who expresses unpleasant thoughts about dental treatment. When it is known in advance that a child 
is over concerned, the dentist should take the time to explore with the parent the reasons for the apprehension in order to know better how to manage it.

Truly frightened children may follow elther regressive or aggressive patterns in an attempt to escape from the situation. A regressive child may cry softly, usually will not communicate with the dentist, and tends to over-react to any distress or anticipated distress. Treatment of this child requires more time and patience, more thorough explanations of procedures, and avoidance of force or threats. Kindly firmness, however, often will be helpful. The aggressive child often will outwardly attack his situation, either verbally or physically. This behaviour may result from over permissive parents, parents who are frightened of the child, or from homes with marital discord. This child requires a strong compatriot he can trust. A firm, honest, and kindly attitude from the outset on the part of the dentist usually will develop the aggressive child into a good patient and a true friend in short order. Firmness of words and voice, without physical restraint, generally solves the problem. Controlled physical restraint to initiate a procedure may be required on occasion.

It is not always possible to categorize behaviour. When in doubt the dentist should treat the behavioural problem as though it were a regressive problem, i.e., with patience and kindness and without an undue display of authority. Too much firmness can cause a regressive child to retreat further. If the "sweet" approach does not solve the problem, firmer measures may be required. With behavioural problems usually it is best to separate the child from the parent, although this should not be an irrevocable rule. Usually the dentist can establish rapport more readfly if the parent is not present for the child to react to.

\section{The immature child}

Children under the age of two are usually too immature to understand well enough the instructions of the dentist. Hence, it is difficult to develop a sense of trust and confidence so that dental procedures can be carried out in a routine fashion. Very young children generally require dental care because of injuries or a high degree of caries susceptibility. The treatment needs following injuries are often minimal and require but one short appointment. For example, if a primary incisor must be extracted for a child too young to understand, the parent can hold the child in her lap, the assistant can stabilize the child's head, and the dentist can adminlster the local anæsthetic and remove the tooth. Pain and psychologic trauma are minimal and soon forgotten.

If an immature child requires several appointments for extensive treatment, the dentist must weigh carefully the merits of conventional treatment versus treatment under a general anæsthetic. Premedication and local anæsthetics may solve the problem for some children. Often, however, so much premedication is required to produce adequate tranquillity that the hazards do not justify its use. General anxsthesia then becomes the logical choice. Neither the use of premedication nor general anæsthesia should be taken lightly. A single mishap is one too many.

\section{Handicapped children}

There are many handicapping conditions which have a bearing on dental health and require modifications in dental treatment. Mental retardation, cerebral palsy, and emotional disturbances are handicapping problems which influence behaviour and the abllity of the dentist to provide service. Whereas these three handicaps are very different, they have one thing in common; they make dental treatment more difficult, but by no means Impossible. If the child has the mental capacity to understand to the extent that rapport with the dentist can be established, then treatment can be provided in routine fashion. The cerebral palsied youngster, with athetold movements, can be supported in the dental chair with restraining devices that minimize his sudden bounces, making treatment possible and giving him a feeling of greater security.

When the degree of mental retardation or emotional disturbance precludes cooperation, then premedication or general anæsthesia will be required. These adjuncts, however, should not be used automatically just because a child is labelled "handicapped". Many parents of handicapped children do not seek dental treatment for their children because they are unaware that it is available. The profession should do a better job in carrying the message that dental care is avallable to all children regardless of any handicapping condition. 
The use of premedicants

The use of drugs to medicate children prior to dental appointments has become rather popular in the United States. There are, however, many differing opinions as to indications for the drugs, the specific drug to use, and its dosage. Some dentists premedicate most of their child patients regularly to make dental treatment smoother. One wonders if this philosophy is to aid the child or the dentist. Other dentists premedicate only when there is a specific need. Such needs include, (1) the normal child who is over concerned and for whom tranquillizing drugs are helpful in permitting him to accept treatment more gracefully, (2) the immature child who is too young to understand and cooperate, and (3) the handicapped child who lacks the mental capacity, the emotional stability, or the physical ability to cooperate.

Many drugs have been used to premedicate child patients with varying degrees of success. There is no one drug or combination of drugs that solves all problems. Among the drug types that have been used are, (1) sedatives and hypnotics (barbituates, chloral hydrate, promethazine), narcotics (meperidine, morphine), (3) tranquillizers (chlorpromazine, meprobamate), (4) muscle relaxants (mephenesin, zoxazalamine), (5) ataractics (Atarax), and (6) antisialogogues. It should be obvious that one must possess complete knowledge of the actions, the dosages, and the side effects of any drug that is selected. Chloral hydrate, used alone or in combination with Atarax, is being used rather widely with reportedly good results.

The use of general anzesthesia

Occasionally, dentistry cannot be performed unless the patient is asleep. The word "occasionally" should be emphasized because few patients cannot be treated in a conventional fashion and because the use of general anæsthesia carries additional responsibilities and hazards. In the Ann Arbor area (population 150,000), 10 to 12 child patients receive complete dental care annually under general anæsthesia. It is likely that additional patients who require this form of treatment simply do not seek it. Even so, the number of patients requiring general anæsthesia is small. All such patients receive this treatment in a hospital. This does not necessarily rule out the private office as a site, but the offlce must be equipped and staffed as is the hospital so that all precautions are taken to prevent mishaps.

A preoperative health examination is mandatory. This should include a complete health history, a physical examination, chest $X$-rays, and laboratory studies of the blood and urine. To minimize psychologic trauma of the hospital experience, especially for the very young child, it is advisable for the parent to remain with the child until he is put to sleep and be at his side when he awakens. Newer hospitals are providing facilities for the mother to be housed in the same room as the child if the child remains overnight.

The quality of dental service provided under general anæsthesia should equal that provided under conventional circumstances. Under general anæsthesia there is no reason why the rubber dam, high speed rotary instruments, and high volume evacuation cannot be used effectively.

\section{Conclusions}

A child's behaviour should rarely be a deterrent to good dental care. An early first visit, the esiablishment of good dentist-patient relations, and distressless, efficient treatment procedures, will produce a receptive, happy patient for a lifetime. There is no effective substitute for this scheme. Premedication may be useful in specific instances but highly disappointing in others. Premedicating drugs should be used only with the full knowledge of their actions and side effects. General anæsthesia may be employed when other conventional control measures fail.

The University of Michigan, Ann Arbor, Michigan, U.S.A. 